\title{
KUZEY KAFKASYA (STAVROPOL) TÜRKMEN EDEBİYATINDA MAHTUMKULU
}

\author{
MAHTUMKULU IN NORTHERN CAUCASIAN TURKMENS \\ LITERATURE
}

Savaş ŞAHIN**

\begin{abstract}
$\ddot{O} z$
17. asırda Maňgışlak, Üstyurt ve Balkan'dan Rusya'ya göç eden Kuzey Kafkas Türkmenleri 1677 yılında öncelikle Astrahan'a yerleşmişlerdir. Daha sonra ise Stavropol'da Kuma ve Terek Nehri boylarına yerleşen Türkmenler burada irili ufaklı on beş civarında köy kurmuşlardır. Kafkas Türkmenleri bugün Stavropol ve Astrahanda yaklaşık yirmi köyde yaşamaktadır. Stavropol Türkmenleri günümüzde dillerini kaybetme tehlikesiyle karşı karşıya olan topluluklardandır. Kafkas Türkmenleri geçmişte dillerini, edebiyatların, kültürlerini koruma konusunda büyük çabalar harcamışlar, kısmen yazılı çoğunlukla sözlü bir edebiyat meydana getirmişlerdir. Kendi soylarından gelen büyük şairleri Mahtumkulu'yu uzak coğrafyalarda olsa bile unutmamışlar şiirlerini toylarda, meclislerde ezbere okumuşlardır. Bu çalışmada, Mahtumkulu'nun şiirlerinin Türkmenistan ve Kuzey Kafkasya Türkmenleri arasında bilinen nüshaları karşılaştırılacaktır. Ayrıca, Türkmenistan nüshasında bulunmayan Mahtumkulu şiirleri de yer alacaktır.
\end{abstract}

\section{Anahtar Kelimeler}

Kuzey Kafkasya (Stavropol) Türkmenleri, Stavropol, Mahtumkulu, Magtymguly.

\begin{abstract}
The northern Caucasian Turkmens who migrated from Mangishlak, Üstyurt and Balkan to Russia in the 17th century first settled in Astrakhan in 1677. Later on, the Turkmen settled in the towns of Kuma and Terek in Stavropol founded here about 15 small villages. The Caucasian Turkmens today live in about twenty villages around Stavropol and Astrakhan. Stavropol Turkmens are the communities facing the danger of losing their language today. The Caucasian Turkmens have spent great efforts to preserve their language, literature, and culture. The great poets who came from their own lore read the Mahtumkulu by heart in the parliaments, even though they had not forgotten it in distant geographies. In this study, the copies of Mahtumkulu's poems known between Turkmenistan and Turkmen of the North Caucasus will be compared. In addition, Mahtumkulu poems that are not found in the Turkmenistan version will also take place.
\end{abstract}

\section{Keywords}

Northern Caucasus(Stavropol) Turkmens, Stavropol, Mahtumkulu, Magtymguly.

\footnotetext{
* Dr. Öğr. Üyesi, Akdeniz Üniversitesi Edebiyat Fakültesi Türk Dili ve Edebiyatı Bölümü, savasss154@gmail.com
} 


\section{Gíriş}

Günümüzde yedi yüzden fazla şiiri ve on kadar küçük çaplı poeması (şiirsel hikâyeleri) bulunan Mahtumkulu'nun Türk dünyasının birçok yerinde elyazmaları eserlerine rastlanmaktadır. Şairin birçok şiiri de halk dilinden derlenmiştir (Aşırov 2012:14). Şairin şiirleri, Türkmenler tarafından zevkle okunmuş, beğenilmiş, türkü hâline getirilerek bahşılar tarafından çalınıp söylenmiştir. (Aşırov 1984:11). Bahşılar, Mahtumkulu'nun şiirlerini ezbere bildikleri için divanı görmeden okumadan ezbere yazmışlar, yazdırmışlardır. Bu el yazmalarının çoğunun içinde Durdı, Talıbı, Zelilî, Şabende, Mollanefes, Misginkılıç gibi Türkmen klasik şairlerinin şiirleri de bulunmaktadır (Yılmaz 2005:16). Mahtumkulu Adındaki Dil ve Edebiyat Enstitüsü'nün el yazma eserlerinin birçoğunu halk bahşılarının dilinden yazılıp alınan eserler oluşturmaktadır (Çarıyev, 1989:281-283).

18. yüzyılın ikinci yarısında Türkmenler arasında meşhur olan Mahtumkulu, birbirilerinden siyasi bakımdan kopuk, dağınık Türkmen kabileleri içinde hepsi tarafından eşit derecede kıymetli görülüyor, Türkmen halkının millî şairi olarak görülüyordu (Çarıyev,1989:280). Mahtumkulu; çok geniş bir coğrafyada tanınan, sevilen, şiirleri ezbere bilinen bir şairdir. Mahtumkulu Kuzey Kafkasya Türkmenleri arasında da oldukça meşhurdu. Kuzey Kafkasya'da 1983 yılında aylarca kalarak Türkmenler arasında dil ve folklor çalışmaları yapan Sapar Kürenov, Türkmen köylerinin hepsinde Mahtumkulu'ya olan sevgiyi gördüğünü ve Stavropol Türkmenlerinin şairin şiirlerini ezbere bildiklerini söylemiştir. Kürenov, Mahtumkulu Destanı'nın çoğunluğu dört az da olsa beş satırdan oluşan dizelerden oluşan kırk civarında şiirini tespit etmiştir. Kürenov günümüzde neşredilen Mahtumkulu Divanları'na Stavropolvaryantlarının eklenmesinin asıl nüshadaki manaların aydınlatılmasına katkısı olacağını söylemiştir (Kürenov 1989, 73-82). Stavropol'da yaptığımız saha çalışmalarında Türkmen bahşıların şiirlerini not ettikleri defterlerin olduğu, şiirleri bu defterden okudukları, toylarda ve meclislerde Mahtumkulu'nun şiirlerini destansı bir şekilde ezgili olarak söyledikleri bilgisini aldık. Stavropol'da Çur Köyü'nde Türkmen bir araştırmacıdan, KuzeyKafkas Türkmenlerinin meşhur bahşılarından Nazar Bahşı'nın not defterini temin ettik. Defterde Bahşı'nın toylarda, meclislerde söylediği Mahtumkula'ya ait olan şiirleri ve Köroğlu destanını not ettiğini tespit ettik. Çalışmamıza konu olan Mahtumkulu'nun şiirleri,Nazar Bahşı'nın defterinden aktarılmıştır.

Çalışmamızda, Mahtumkulu'nun şiirlerinin Stavropol nüshasıyla Türkmenistan'da yayımlanmış olan şiirleri karşılaştırdık. Bahşı'nın defterinde 45 şiir tespit edildi. Stavropol nüshasında eksik olan dörtlükleri her şiirin başında belirttik. Stavropol nüshasında fazla olan dörtlükleri belirterek, bunların Türkmenistan nüshalarında olmadığını gösterdik. Her iki nüshayı karşılaştırma yaparken iki nüsha arasında kelime ya da ses farklılıkları varsa bunları da italik yazı olarak gösterdik. Bahşı'nınkelimeleri açıklarken parantez içine aldığı kelimeleri olduğu gibi ekledik.Türkmenistan nüshasında olmayan şiirleri de tablo dışında gösterdik. Bu çalışmanın Mahtumkulu'nun çözümlenemeyen ya da anlaşılamayan şiirlerinin çözümlenmesine katkı sağlayacağı düşünülmektedir. Ayrıca, yüzyıllar önce anavatanlarından göç etmek zorunda kalan Kuzey Kafkasya Türkmenlerinin dillerinin anlaşılması bakımından çalışmamızdaki dil malzemesinin araştırmacıların çalışmalarına katkı sağlayacağı düşünüyoruz. 


\section{Mahtumkulu'nun Hayatı ve Edebî Kişiliği}

Türkmenlerin en büyük şâirlerinden biri olarak kabul edilen Mahtumkulu genel bir kabulle 1733-1782 yılları arasında yaşamıştır. Araştırmacılar, şâirin doğumunu 1733'lü yıllara yakın olduğu noktasında beyanlarda bulunmuşlardır (Cankurt 2013:912-913). Şâir, Etrek boyunda yer alan "Hacıgovşan" Hacı Kavuşan köyünde dünyaya gelir. Mahtumkulu Göklen boyunun Gerkez kabilesindendir .Bütün şiirlerinin konusunu halkın gerçek hayatından alan şâir ayrıca vatanseverlik, kahramanlık gibi konuları işlemiş, Türkmen mertliğini ortaya koymuş, hayatı boyunca Türkmen birliğini sağlamaya çabalamıştır (Sarıyev 2008:3809-3810).Türkmenlerin klasik edebiyatı dediğimiz dönem, 18. yüzyılda başlar. 18. yüzyıl edebiyatı halka yakın, halkın sıkıntılarının halkın diliyle anlatıldığı bir dönemdir. 18. yüzyılda Mahtumkulu ile birlikte, Azadı, Andalıp, Magrupı, Şabende, Gayıbı, Şeydayı gibi şâirler Klasik Türkmen Edebiyatı'nın temellerini atmışlardır (Garrıyev 1975:9).

Mahtumkulu; yücelik, erdem ve fazilet vasıflarını dünyaya gelirken taşıyan büyük bir şairdir. Edebiyata, ilme susamış bir genç olarak değişik medres ve mekteplerde eğitim almış, Doğu'nun büyük âlimlerinin eserlerini okuyarak bilgisini artırmış, böylelikle devrin güçlü, dirayetli bir bilim adamı ve şairi olarak yetişmiştir (Gulla 1998:183). Türkmen boylarını birleştirmeyi isteyen, vatanın birlik ve beraberliğini arzulayan, 18. yüzyılın Türkmen hayatını, toplumun aksayan yönelerini, o dönemin siyasal ve sosyal şartlarını dile getiren Mahtumkulu aynı zamanda şiirlerinde insan sevgisini, güzel ahlâkı, erdemi, beşeri aşkı halkın anlayabileceğ $i$ bir dilde âdeta bir oya gibi işlemiştir. Fuad Köprülü Mahtumkulu'nda Ahmed Yesevi'nin tesirleri olduğunu belirttmiş (Köprülü 1976:177) şâirin dini konularla ilgili şiirleri halkın anlayabileceği sadelikle işlediğni söylemiştir.

Derin bir maneviyatın hissedildiği şiirlerinde kullandığı dilin anlam yönüne hâkim olmuş, söz sanatlarını etkili biçimde kullanmış, halk ağzını kullanarak geniş kitlelere hitâp edebilmiş, eserlerinde dünya görüşünü, hayat felsefesini yansıtırken de anlam ve mecazla ilgili sanatları da oldukça etkili bir biçimde kullanabilmiştir (Erdem 2012:73). Mahtumkulu Türkmenlere has mahalli temaları ve söyleyiş tarzını bırakmadan, kısmen farklı nazım şekilleri içinde, Yunusla başlayan tsavvuf ve ilahi aşk konusunu, Karacaoğlandaki lirizm çizgisini takip ederek bütün Türkmen edebiyatının ışığı olmuştur. (Türkmen 2009:22).

Şâirin şiirlerindeki muhtevayı yaşadığı dönemle ilişikilendirmek ve yaşadığı dönemle olan bağlantısını ortaya koymak Mahtumkulu'yu anlamada oldukça önemlidir.

Mahtumkulu'nun yaşadığı 18. yüzyıl dış tehditlerin yanında, iç çekişmelerin de devam ettiği, yerel idarecilerin halka zulmettiği bir dönemdir. Türkmenler bu şartlarda yerleşik hayata geçmeye başlamıştır. Mahtumkulu, işte böyle bir ortamda doğmuş, yetişmiş ve eser vermiştir (Temizkan, 2010:174). Mahtumkulu Türkmen coğrafyası dişında Hindistan, Kâbil, Mergilan, Semerkant, Yesi, Buhara, Hive gibi Türk kültür coğrafyalarında bulunması, burada canlı olarak yaşayan Türk şiir geleneğini Nizamî, Nesimî, Fuzulî veya Nevaî gibi şahsiyetlerin şiir ve anlatmalarını öğrenen, üstatların eserlerini öğrenerek bilgisini artırmıştır (Çetin vd. 2015:84).Mahtumkulu klasik edebiyatı, özellikle de Nevâyî́yi bilmesine rağmen, şiirini Türkmen diliyle ve Türkmenlerin anlayıp benimseyeceği bir tarzda yazmıştır. Şiirlerinde henüz yazı dili olarak kullanılmayan Türkmen şivesinin kelime olarak, söyleyiş tarzı olarak yer aldığı görülür (Biray 1992:15). 


\section{Mahtumkulu'nun Şiirlerini Kuzey Kafkasya (Stavropol) ve Türkmenistan' da Yayımlanan Nüshalarının Karşılaştırılması}

“Mahtumkulu'nun kendi eliyle yazdı̆̆ı divan kaybolmuş, birine dikte ettirdiği şiirleri de bir dağ mağarasında çıkan yangında yanmıştır. Sonra çeşitli müstensihler topladıkları şiirleri divan hâline getirmişler. Bu yüzden de yazılan metinlerin çoğunda şiirlerin düzeni farklı ama çoğunun en başında "Bir gîce yatīrdım tüniň yārında" dizesiyle başlayan şiir sunulmuştur. Yüzlerce yazma divanın arasında baştan sona kadar, düzgün ve hatasız olan nüsha yoktur." (Azmun 2012:87).

Mahtumkulu'nun şiirlerinin halk tarafından çok sevilip ve benimsenmesi, halk şairleri tarafından ezbere bilinmesi ve söylenmesi şiirlerin sürekli istinsah edilmesini sağlamıştır. Ele geçirilen Mahtumkulu Divanı devamlı istinsah edilmiş, hatta bahşılar şiirleri ezberlere bildikleri için divanı görmeden, okumadan, ezbere yazmış ve yazdırmışlardır. Bu divanlarda Türkmenlerin diğer önemli şairlerinin şiirleri de bulunmaktadır (Yılmaz 2005:88-89).

Nazar Bahşı'nın not defterinde de Mırat Talıbı'ya ait olduğu düşünülen bir şiir bulunmaktadır. Şiirin son dörtlüğünde Talıbı'nın yerine Mahtumkulu'nun adı geçmektedir. Yine defterin sonunda bir de Leyla ve Mecnun Destanı'ndan bir şiir eklenmiştir. Şairin not defterinde 45 şiir tespit edildi ve bunları Türkmenistan'da yayımlanan divanlarla karşılaştırıldı. Bahşının açıklama amaçlı ekleyip parantez içinede gösterdiği kısımları da olduğu gibi aktarıldı. Türkmenistan yayınlarında olup da Stavropol nüshasında olmayan beyitlerşiirlerin başında, Türkmenistan yayınlarında olmayan dörtlükler ise tablodabelirtildi. Bahşı'nın defterinde bulunan ve Mahtumkulu'ya ait olan şiirler sırasıyla şunlardır:

\section{Gözel Şirgazı (1959:145-146) (4.5.6.7.8. dörtlükler eksik)}

\begin{tabular}{|c|c|}
\hline Stavropol & Türkmenistan \\
\hline 1/1Mekan tutıp üç yıl iydim duzuñ & Mekan eyläp üç yıl iydim duzuñı, \\
\hline 2/2Sende bilim aldım, açıldı dilim. & Sende taglım aldı, açıldı dilim, \\
\hline 3/2Dost, duşman, gardaşım, hakı-yaranı, & Dost, rakıp, gardaşım, hakı-yaranı, \\
\hline 4/1Caşgun yüregime mövç urar, yatmaz & Coşgun yüregime möwç urar, yatmaz, \\
\hline 5/1Kutbda say gözläp kemana (yay) düşdüm, & $\begin{array}{l}\text { Kutbda say gözläp ummana duşdum, } \\
\text { aşdım, }\end{array}$ \\
\hline
\end{tabular}

2. Turkmeniň (1959:13-14) (2.6.8. dörtlükler eksik)

\begin{tabular}{|l|l|}
\hline Stavropol & Türkmenistan \\
\hline 1/1Amu Derya bile Kaspiy arası, & Ceyhun bile Hazar arası, \\
1/2Çöl üstinden öser yeli turkmeniñ, & Çöl üstünden öser yeli turkmeniñ, \\
\hline $\begin{array}{l}\text { 2/1Al-yaşıl purenip çıkar perisi (perizadı, } \\
\text { 2/2Kükseyip betiñe urar güliñ isi, }\end{array}$ & Al-yaşıl bürenip çıkar perisi, \\
\hline 4/3Bir suprada hazır kılıpsa aşlar, & Kükeyip bark urar anbarıñ ısı, \\
\hline 5/3Bilbilden ayrılıp, solup sargaymaz, & Bir suprada tayyar kılınsa aşlar, \\
\hline 6/4Magtımgulı sözler, tagrıfın turkmeniñ. & Bilbilden ayrılıp, solup saralmaz, \\
\hline
\end{tabular}


3. Oglum Azadi'm (1959:25-27)

\begin{tabular}{|l|l|}
\hline Stavropol & Türkmenistan \\
\hline 2/2Baş alıp, nire gideli? & Baş alıp, kayda gideli? \\
2/3Oturıp-turşı̈̈dalı (ädebli) & Oturıp-turşı edall, \\
\hline 3/3Gaşını çıtmanotran. & Gaşını çıtmay oturan. \\
3/4Gözleri gülen islerin. & Gözleri gülen islärin. \\
\hline 4/2Hezl etmedim, dünyä, senden, & Häzl etmedim, dünyä, senden, \\
4/3Dili datlı süyci, lebi handan, & Tili süyci, lebi handan, \\
4/4Bir yagşı yoldaş islärin. & Bir goyna salan islerin. \\
\hline 5/1Magtımgulı, ildim cahana, & Gul Magtım, geldim cahana, \\
\hline & \\
\hline
\end{tabular}

\begin{tabular}{|c|c|}
\hline Stavropol & Türkmenistan \\
\hline $\begin{array}{l}\text { Atası: } \\
\text { 1/3Günde yüz pikr geler-geçer bu başa, } \\
\text { 1/4Köñlümi agırtma, sözümi yıkmagıl, oglum. }\end{array}$ & $\begin{array}{l}\text { Azadi: } \\
\text { Günde yüzköy geler-geçer bu başa, } \\
\text { Agırtma, sözümi yıkmagıl, oglum. }\end{array}$ \\
\hline $\begin{array}{l}\text { Magtımgulı: } \\
\text { 2/1Uyalardım sırım paş eymmezdim, } \\
\text { 2/3Mende-de yüz oy geler geçer her gün bu başa } \\
\text { 2/4Köñil isler, sapar kılsak, Atacan! }\end{array}$ & $\begin{array}{l}\text { Magtımgulı: } \\
\text { Utanardım (Uyalardım) sırım paş } \\
\text { eylemezdim, } \\
\text { Yüz köy geler geçer her gün bu başa, } \\
\text { Köñil istär, sapar kılsak, Azadım! }\end{array}$ \\
\hline $\begin{array}{l}\text { Atası: } \\
\text { 3/1Cepa urma, özün çagır mövlanı, }\end{array}$ & $\begin{array}{l}\text { Atası: } \\
\text { Cepa urma, özüň goyma watanı }\end{array}$ \\
\hline $\begin{array}{l}\text { Atası: } \\
\text { 5/2Bu yol bek beyhudadır (korkunıçlıdır) sen } \\
\text { gidesiñ bar. } \\
\text { 5/3Gel, gitmegil, senden köp dilegim bar, }\end{array}$ & $\begin{array}{l}\text { Atası: } \\
\text { Bu yol beyhudadır sen gidesiñ bar, } \\
\text { Gel, gitmegil, olgum çoh terhosım bar, }\end{array}$ \\
\hline $\begin{array}{l}\text { Mahtımgulı: } \\
\text { 6/1Kalbıma giripdir gitmek hövli, } \\
\text { 6/3Köñlüm keri gaytarma, kılma terhosı) }\end{array}$ & $\begin{array}{l}\text { Mahtımgulı: } \\
\text { Kalbıma giripdir gitmek hövesi, } \\
\text { Köñlüm narov etme, kılma terhosı, }\end{array}$ \\
\hline $\begin{array}{l}\text { Atası: } \\
\text { Kuran okap izgil, yagşı kelamdır, } \\
\text { Rahimsız ovgandır, dini İslamdır. } \\
\text { Garakçıdır yollar, hızdır, haramdır. } \\
\text { Ölersin, yitersin, gitmegil, oglum. }\end{array}$ & Türkmenistan nüshasında yok. \\
\hline $\begin{array}{l}\text { Magtımgulı: } \\
\text { Göreyin, sınayın, bu gün ıkbalım (bahtım), } \\
\text { Yagşı günü - sähet gelib mi salım (ömrüm). } \\
\text { Kast edip, canımga, yetse acalım, } \\
\text { Bu yerde hem bolsa tapar, Atacan! }\end{array}$ & Türkmenistan nüshasında yok. \\
\hline
\end{tabular}




\begin{tabular}{|l|l|}
\hline Atası: & Türkmenistan nüshasında yok. \\
Dövletmemmet diyir, birge sapa süreli, & \\
$\begin{array}{l}\text { Eysem, yibereli, sınap göreli, } \\
\text { “Ämin"diy, tor, oglum, pata bereli, } \\
\text { Bir “Alla” yar bolsun saña, git, oglum! }\end{array}$ & \\
\hline $\begin{array}{l}\text { Magtımgulı: } \\
\text { 10/2Könül talvas, urar, gezer yırakdan, } \\
\text { 10/3Her yerde saglıgım iste(dim) ol handan } \\
\text { 10/4Doga kılıp, hana yalbar, Atacan! }\end{array}$ & $\begin{array}{l}\text { Magtımgulı: } \\
\text { Könül talvas, urar, gezer irakdan, }\end{array}$ \\
& Her yerde saglıgım iste ol hakdan, \\
\hline
\end{tabular}

\section{Gidici Bolma(1959:71-75)}

\begin{tabular}{|l|l|}
\hline Stavropol & Türkmenistan \\
\hline 1/1Gel, köñüm, men saña nesihat äyläyin! & Gel, eý, köňlüm, saňa nesihat kylaý: \\
\hline $\begin{array}{l}\text { 4/1Mert oglıdır, ile yayar desterhan, } \\
\text { 4/2Dogrı söz üstinde berercan, } \\
\text { 4/3Ömrüni ötgerer, diymez bir yalan, }\end{array}$ & $\begin{array}{l}\text { Mert ogludyr, ilge ýazar desterhan, } \\
\text { Dogry söz üstünde berer şirin can, } \\
\text { Ömrüni ötgürep diýmes bir ýalan, }\end{array}$ \\
\hline 6/3Rahimsiz zalımlar bagrı daş bolar, & Rehimsiz zalımlar bagrı daş bolar, \\
\hline $\begin{array}{l}\text { 7/1Men didim bir niçe pendi-nesihat, } \\
\text { 7/3Pesihat bilmegil, barçası nesihat, }\end{array}$ & $\begin{array}{l}\text { Men diydim bir niçe pendi-nesihat, } \\
\text { Pesihat bilmegil, barça nesihat, }\end{array}$ \\
\hline $\begin{array}{l}\text { 8/1Magtımgull, gövnüñdedir köp ärman } \\
\text { 8/3Yetişer bir gün hakdan bir perman }\end{array}$ & $\begin{array}{l}\text { Magtımgulı, gövnüñdedir köp arman } \\
\text { Yetişer bir güni hakdan bu perman, }\end{array}$ \\
\hline
\end{tabular}

\section{Atamıň (2014:31) (4.5. dörtlükler eksik)}

\begin{tabular}{|c|c|}
\hline Stavropol & Türkmenistan \\
\hline $\begin{array}{l}\text { 1/2Geldi acal yolun tutdı atamıñ. } \\
\text { 1/3Bu dünyäniñ işi beylemaş (äzelden) belli } \\
\text { 1/4Ölerüniñ uzınlıgın (tanapın) kesdi atamiñ. }\end{array}$ & $\begin{array}{l}\text { Turdı acal yolun tusdı atamıñ. } \\
\text { Bu dünyäniñ işi beylemiş beli } \\
\text { Ömrüniñ tanapın kesdi atamıñ. }\end{array}$ \\
\hline $\begin{array}{l}\text { 2/2Bu dünyäniñ eşredinisöyledi, } \\
\text { 2/3̈̈sgi şaldan (peşmetden) artık geyim geymedi } \\
\text { 2/4Ahırat öyi boldı atamıñ. (kasdı eksik) }\end{array}$ & $\begin{array}{l}\text { Bu cahanıň eşretini söymedi, } \\
\text { Eski şaldan artık puseş geymedi } \\
\text { Ahret öyi boldı kasdı atamıñ. }\end{array}$ \\
\hline $\begin{array}{l}\text { 3/3Müñ kür bitmez (işanmaz) muhsınlarıñ şeki } \\
\text { yok. } \\
\text { 3/4Pıgamber dostudır, dostı atamıñ. }\end{array}$ & $\begin{array}{l}\text { Müñ̃ür bilmez muhlısları̃ şeki yok, } \\
\text { Pıgamber destidir, desti atamıñ. }\end{array}$ \\
\hline $\begin{array}{l}\text { 4/1Älem (alam) (bu pani dünyäde) içreadam } \\
\text { galmaz, at galar, } \\
\text { 4/4Yerde hoşvakt (rahat) yatar teni atamın. }\end{array}$ & $\begin{array}{l}\text { Älem içre adam galmaz, at gezer, } \\
\text { Yerde hoşvagt yatar postı atamıñ. }\end{array}$ \\
\hline 5/1Magtımgulı, gizle (sakla) sırıñ bar içde, & Magtımgulı, gizli sırı̃ bar içde, \\
\hline
\end{tabular}

\section{Kerem İslärin (2014:168)}

\begin{tabular}{|l|l|}
\hline Stavropol & Türkmenistan \\
\hline 2/2Baş alıp, nire gideli? & Baş alıp, kayda gideli? \\
2/3Oturıp-turşı ädalı (ädebli) & Oturıp-turşı edalı, \\
\hline
\end{tabular}




\begin{tabular}{|l|l|}
\hline 3/3Gaşını çıtmanotran. & Gaşını çıtmay oturan. \\
3/4Gözleri gülen islerin. & Gözleri gülen islärin. \\
\hline 4/2Hezl etmedim, dünyä, senden, & Häzl etmedim, dünyä, senden, \\
4/3Dili datlı süyci, lebi handan, & Tili süyci, lebi handan, \\
4/4Bir yagşı yoldaş islärin. & Bir goyna salan islerin. \\
\hline 5/1Magtımgulı, ildim cahana, & Gul Magtım, geldim cahana, \\
\hline
\end{tabular}

\section{Turgıl Diydiler(2014:11)(2.4.5. 8.9.10.11.12.13.14.15. dörtlükler eksik)}

\begin{tabular}{|l|l|}
\hline Stavropol & Türkmenistan \\
\hline 1/2Bir tört atlı gelip: “Turgul!”diydiler. & Bir dört atlı gelip: “Turgul!”diydiler. \\
\hline 2/1Aldılar-gitdiler, durgan yerimden, & Habarımız bar saña, pursat cayında \\
\hline $\begin{array}{l}\text { 4/1Bir atıñ ardına meni aldılar, } \\
\text { 4/2Seyranda şol cal barıp durdılar, }\end{array}$ & İki divana tutdı golumdan, \\
\hline 5/4“ítirlen cayında goygul” diydiler. & Bir atıñ ardına bizi berdiler, \\
\hline 6/3Mest iner dek ak köpükler saçıpdır, & Sayramda şol caya barıp durdılar, \\
\hline
\end{tabular}

8. Her Yana (1958:148-149) (5. dörtlük eksik)

\begin{tabular}{|l|l|}
\hline Stavropol & Türkmenistan \\
\hline $\begin{array}{l}\text { 1/3 Ya, Yaradan, bir hemra ber! } \\
\text { 1/4Köp muşakat degdi cana. (duşdi bu başa). }\end{array}$ & $\begin{array}{l}\text { Ya Yaradan, bir yar bergil, } \\
\text { Köp muşakgat degdi cana. }\end{array}$ \\
\hline 3/2Kadırsıza yoldaş etme! & Nägadıra yoldaş etme, \\
\hline 4/2Doga kılıp, eliñ gergil, & Diyr sen doga kıl, el gergil, \\
\hline 5/1Yagşı ayal öle gelmez (düşmez), & Yagşı ayal ele gelmez, \\
\hline $\begin{array}{l}\text { 6/1Magtımgulı, yansam-bişsem, } \\
\text { 6/3Hövesim bar, bir yar guçsam! } \\
\text { 6/4Diysem sözlerim erkana. }\end{array}$ & $\begin{array}{l}\text { Magtımgulı, köysem-bişsem, } \\
\text { Hövesim bar, bir giz guçsam! } \\
\text { Diysem sözümi erkana. }\end{array}$ \\
\hline
\end{tabular}

\section{Gözim Düşdi (2014:127)(2.3. dörtlükler eksik)}

\begin{tabular}{|l|l|}
\hline Stavropol & Türkmenistan \\
\hline 1/4Mestana gözüm düşdi. & Messana gözüm düşdi. \\
\hline 3/2Hızmatta geler gullar, & Hızmata geler gullar, \\
\hline 4/2Ey, cennet içre bir gül, & Ey, cennet era bir gül, \\
\hline 5/2Köyüñde (yoliñda) bolam sergizdan! & Köyüñde bolam nalan \\
5/3Magtımgulı diyir, ey mehriban (can), & Magtımgulı diyr, ey can, \\
\hline
\end{tabular}

10. Başdan Dogrusı (2014:251)(4.6.7.8. dörtlükler eksik)

\begin{tabular}{|l|l|}
\hline Stavropol & Türkmenistan \\
\hline 2/1Köñlümniñ höşgähi -sen, & Gövnümiñ höşgähi sen-sen, \\
\hline 4/2Her kişiden dovran geçer, & Her kişiden dövran geçer, \\
4/3Namart, yiyidin aybın açar, & Namart, yigit aybın açar, \\
\hline
\end{tabular}


5/1Gel, Magtımgull, hemra bolsañ,

5/2Horliga galanı̃̃ gövnüi alsañ

5/3Yagşı bile ömür sürseñ

5/4Ayrılmaz huşdan-şatlıkdan, dogrusı.
Ger, Pıragi, hemra bolsañ,

Naçar galan gövün alsañ

Yagşı bilenoynapgülseñ

Ayrılmaz huşdandogrusı.

11. Ayrıldım (2014:142) (2.3. dörtlükler eksik)

\begin{tabular}{|l|l|}
\hline Stavropol & Türkmenistan \\
\hline 1/4Ol söver yardan ayrıldım. & Ol sövdügim yardan ayrıldım. \\
\hline 2/2Siya saçlı sümbülimden, & Siya saçy sümbülimden, \\
\hline 3/1Däli köñlüm arzımanı, & Däli köñlüm arzumanı, \\
3/3Sekiz cennetiñ bostanı, & Sekiz cennetiñ bossanı, \\
3/4 Bakjalı bagdan ayrıldım. & Bakcalı bardan ayrıldım. \\
\hline 4/1İlleri bar diñli-diñli, & İlleri bar deñli-deñli, \\
4/2Sovuk sovlı, ter ölenli (gülli), & Sovuk suvlı, ter ölenli, \\
\hline 4/3Menzilheni (mekanı) bagı-bostan, & Menzilgähi bagı-bossan, \\
\hline
\end{tabular}

12. Yarım Ya Cepbar! (2014:166)(3.4.5. dörtlükler eksik)

\begin{tabular}{|l|l|}
\hline Stavropol & Türkmenistan \\
\hline 1/3Sansız söyüşdim, öysüz (oysız) ayrıldım & Sangısız söyüşdim, öysüz ayrıldım, \\
1/4Bagışlasañ neyler yarım, ya cepbar! & Bagışlasañ neylär yarım, ya, Alla! \\
\hline 2/2Yüregimde yar hıyalı bar bile, & Yüreginde yar hıyalı bar bile, \\
2/3İmdi, läkin ayırdılar zor bile, & Imdi, leykin ayırdılar zor bile, \\
\hline 3/1Ihlas bilensöymü̧̧̈em men ol yarı, & $\begin{array}{l}\text { Ihlas ile yar meni diyr, men yarı, } \\
\text { 3/2Cövrendicigerim, gitdi kararı, }\end{array}$ \\
\hline $\begin{array}{l}\text { 4/1Sözüm saña yetmez, arzım aytmaga, } \\
\text { 4/2İşimiñ rovacı (rövı-añ bolsun) yokdur yetmege, }\end{array}$ & $\begin{array}{l}\text { Elim saña yetmez, arzım aytmaga, } \\
\text { İşimiñ rovacı (rövı-añ bolsun) yokdur } \\
\text { bitmäge, }\end{array}$ \\
\hline 5/3Günahım köp bolsa, keremıñ kändir(köpdir), & $\begin{array}{l}\text { Cürmümçoh bolsa hem, keremiñ kändir, } \\
\text { 5/4Bagış̧lasañ neyleri yarım, ya cepbar! }\end{array}$ \\
\hline
\end{tabular}

\section{BarmıYaranlar(2. dörtlük eksik)}

\begin{tabular}{|l|l|}
\hline Stavropol & Türkmenistan \\
\hline Bolmuşam mesti-şeyda, & Türkmenistan nüshasında yok. \\
Hezar, pişe, sed sovda, & \\
Halka men dey rısva, & \\
Bolan barmı, yaranlar? & \\
\hline 5/2Rehim etmezler yaş tökse, & Rehim etmezler yaş dökse, \\
5/4Dalan barmı, yaranlar. & Talan barmı, yaranlar. \\
\hline
\end{tabular}

\section{Bu Gün (2014:146)(5. dörtlük eksik)}

\begin{tabular}{|l|l|}
\hline Stavropol & Türkmenistan \\
\hline 2/2Övsün atar övüsip gül, & Övşün atar övüsip gül, \\
2/3Aşık bolsan, munı yat bil, & Aşı bolsaň, munı yat bil, \\
\hline 3/1Tilsenuber şekeristan, & Til senewer şekeristan, \\
3/3Goynuñ içre biten bostan, & Goynuñ içre biten bossan, \\
\hline 4/1Gül destesin tirer bolsañ, & Gül dessesin tirer bolsañ, \\
4/4Totı güftar rövan bu gün. & Totı güftar zıban bu gün. \\
\hline
\end{tabular}


15. Müptela Kıldı (1959:50) (2.5.6.7.8. dörtlükler eksik)

\begin{tabular}{|l|l|}
\hline Stavropol & Türkmenistan \\
\hline 2/1Şumacalabomaz çäre, & Şom ecele olmaz çäre, \\
2/2Cebrinden galdım bu zara, & Cebrinden kaldım bu zara, \\
\hline 2/1 İndi bir dem kararım yok, & Şindi bir dem kararım yok, \\
2/2Bu yerde durarım yok, & Bu menzilde durağım yok, \\
2/4Habarsız binova kıldı. & Habarsız mahrum kıldı. \\
\hline 3/1Mahtımgulı çeker peryat, & Mahtımgulıkıldı feryat, \\
\hline
\end{tabular}

\section{Bagtım Karadır (2014:47) (2.4.6.7.8.9.10.11.dörtlükler eksik)}

\begin{tabular}{|l|l|}
\hline Stavropol & Türkmenistan \\
\hline 3/1Pelege düş gelse, gaçıp gutulmaz. & Pelege duşan aw gaçıp gutulmaz. \\
3/2Tartar okı adam oglı, atılmaz, & Tartan okı adam oglı, atılmaz, \\
3/3Yeke yigidiñ ömür adı tutımnaz & Yeke äriň ömür adı tutulmaz, \\
\hline 4/2Boş galdı dukanım, yok boldı barım, & Boş galdı dukanım, dargadı barım, \\
\hline
\end{tabular}

17. Görülsün İndi (2014:25)(6. dörtlük eksik)

\begin{tabular}{|l|l|}
\hline Stavropol & Türkmenistan \\
\hline 1/4Degme, gan hoş urup, yörülsin imdi. & Degme, ol coş urup, dökülsin indi. \\
\hline 2/1Ozal başda cepbar bar ätdi yoktan, & Ozal başda cepbar bar etdi yokdan, \\
\hline 4/2Düşmana galmasın bütin malımız, & Duşmana galmasın beýtin, malımı, \\
4/4Tañra gerek bolsa, berilsin imdi. & Tañra gerek bolsa, alınsın indi. \\
\hline
\end{tabular}

18. Mala Seretmez (2014:334)(4.5.6. dörtlükler eksik)

\begin{tabular}{|l|l|}
\hline Stavropol & Türkmenistan \\
\hline 1/3Dogmadık oguldan, gardaş är yagşı, & Dogmadık oguldan, dogan dag yagşı, \\
\hline 2/1Atda ayak bolsa, özge sın bolmaz, & Atda ayak bolsa, başga sın bolmaz, \\
2/3Soveş güni goç yigitde müyn bolmaz, & Söveş güni goç yigitde üyn bolmaz, \\
2/4Garşı durar,ötkir yaya seretmez. & Garşı bakar, peykam yaya seretmez. \\
\hline 3/3Kimseler bukılıp, kimseler at uşlar, & Kimse adam yıkıp, kimseler at uşlar, \\
3/4Abıray tapmasa, paya (olca) seretmez. & Abray tapmasa, paya seretmez. \\
\hline 4/1Magtımgulı, garıp gövnün bay edip, & Magtımgulı, garıp könlün bay edip, \\
4/2Kanagat ülkesin, bendi-cay edip, & Kanagat ülkesin, bende-cay edip, \\
\hline
\end{tabular}

19. Gerekdir (1959:3) (1. dörtlük eksik)

\begin{tabular}{|l|l|}
\hline Stavropol & Türkmenistan \\
\hline 1/3Goç yigitler il üstinde, & Goç yigitler il üstünde, \\
1/4Namıs bilen har gerekdir. & Namıs bilen ar gerekdir. \\
\hline 2/2Sıpra yayıp nan tökmege, & Saçak yazyıp, nan dökmege, \\
2/3Abray alıp, at etmege, & Abray alıp, at etmäge, \\
2/4Golunda malı gerekdir. & Golda malı gerekdir. \\
\hline 3/3Goç yiğide- ar gılıcı, & Goç yiğide- ar galıcı, \\
\hline
\end{tabular}

20. Meydan Yoluksa (2014:333) (3. dörtlük eksik) 


\begin{tabular}{|c|c|}
\hline Stavropol & Türkmenistan \\
\hline 3/3Yigit ölse, hengam galar dovranlı, & Bedew ölse, meydan galar armanlı, \\
\hline $\begin{array}{l}\text { 4/3Cay yerinde gayra galsa kartaydar, } \\
\text { 4/4Goç yigide haşañ at yoluksa }\end{array}$ & $\begin{array}{l}\text { Cay yerinde ize galsa garrıdar, } \\
\text { Goç yigidiň atı çaman yoluksa }\end{array}$ \\
\hline $\begin{array}{l}\text { 5/2Mert çeker gaygısın ilin-yuvurdiñ, } \\
\text { 5/4Çındır diyip gaçar tuman yoluksa. }\end{array}$ & $\begin{array}{l}\text { Mert çeker täsibin ilin-yuwurduñ, } \\
\text { Cendir diyip gaçar duman yoluksa. }\end{array}$ \\
\hline $\begin{array}{l}\text { 6/1Magtımgul, övüt bergil söz bile, } \\
\text { 6/4Namart özin gizler, mihman yoluksa. }\end{array}$ & $\begin{array}{l}\text { Magtımgulı, övüt bergin söz bile, } \\
\text { Namart özin gizlär, mihman yoluksa. }\end{array}$ \\
\hline
\end{tabular}

\section{Deňi-Duşumız (1.5. dörtlükler eksik)}

\begin{tabular}{|l|l|}
\hline Stavropol & Türkmenistan \\
\hline 1/2Taratdı her yaga deňi-duşumız, & Dargatdı her yana deňi-duşumız, \\
1/4Gızılbaşlar alıp, vayran eyledi. & Gizılbaşlar alıp, veyran eyledi. \\
\hline 2/2Niceler ızında sarayıp-solup, & Niceler ızında sargayıp-solup, \\
2/3Kimi berip, anıñ bahasın alıp, & Kimi berip, onuñ bahasın alıp, \\
\hline 3/2Aglamakdan gül yüzlerim soldırdı, & Aglamakdan gül yüzlerim soldurdı, \\
3/4Duşmanımı şat-şadıman eyledi. & Duşmanımı ceyhun derya eyledi. \\
\hline 4/1Köydürer şum pelek giñ cebri-capanı, & Köydürer şum pelek giñ cebri-cepası, \\
4/3Mahtımgull, yokdır bu sözümiñ hatası, & Magtımgulı, yokdır bu sözümiñ hatası, \\
4/4Pelek elip kaddım "dal" eyledi. & Pelek elip kaddım duta eyledi. \\
\hline
\end{tabular}

\section{Yörmeli Boldı (2014:26)}

\begin{tabular}{|l|l|}
\hline Stavropol & Türkmenistan \\
\hline $\begin{array}{l}\text { 1/3Niçe zahmet çeken canlar, } \\
\text { 1/4Cepana görmeli boldı. }\end{array}$ & Nice zähmet çeken canlar, \\
& Cepanı görmeli boldı. \\
\hline 2/2Arada göydi şirin can, & Arada köydi şirin can, \\
2/3 Üstimizde rehimsiz han, & Üstümizde rehimsiz kan, \\
\hline
\end{tabular}

\section{Gulana Göklen (1959:6)(2.4.5.6. dörtlükler eksik)}

\begin{tabular}{|l|l|}
\hline Stavropol & Türkmenistan \\
\hline 3/2Güycı artar, Rum zarı dek, & Güyci artar, Rum zorı dek, \\
3/3Alaşarsın, sen, aç böri dek, & Aslışar sen, sen, aç böri dek, \\
Işk edip meydana, Gökleñ! & Işk edip meydana, Gökleñ! \\
\hline Gahırman mertleriñ girer söveşe, & Türkmenistan nüshasında yok. \\
Dövletiñ öñünden, (aldınkıdan) arta, & \\
Gılıç urup gızılbaşa, & \\
Dolar sen Gürgene, Gökleñ! & \\
\hline
\end{tabular}

\section{4. Öňi Ardı Bilinmez(1959:5)(2. dörtlük eksik)}

\begin{tabular}{|l|l|}
\hline Stavropol & Türkmenistan \\
\hline 1/1Yomut, Gökläñ tagsıp edip özinden, & Yomut, Gökläñ tagsıp edip özünden, \\
1/2Çıksa goşun, aldı izi bilinmez, & Çıksa goşun, öňi-ardı bilinmez, \\
\hline 2/3Dökülerler, galaları̃ alarlar, & Teke, salır yöriş etse yokardan \\
\hline
\end{tabular}


3/1Ehli iller hav çekip gelerler,

3/2Galañ yıkıp, tagtıñ tartıp alarlar,

3/3Dökülerler, galalarnı alarlar,

3/4Yaginiñ namardi, merdi bilinmez.
Ähli iller namıs edip gelerler,

Galañ yıkıp, tagtıñ berbat kılarlar,

Dökülerler, galalarıň alarlar,

Bu kentleriň üçi, dördi bilinmez.

25. Yaşımız (1959:4)(2. dörtlük eksik)

\begin{tabular}{|l|l|}
\hline Stavropol & Türkmenistan \\
\hline 2/1Dervüşler köñli cem dursun namaza, & Dervüşler köñli cem bolsun namaza, \\
\hline 4/2Galmadık biz gizılbaşıñ horlugna, & Galmalıň biz gizılbaşıñ horlugna, \\
\hline
\end{tabular}

26. Zarlar İçinde (2014:18) (4. dörtlük eksik)

\begin{tabular}{|l|l|}
\hline Stavropol & Türkmenistan \\
\hline $\begin{array}{l}\text { 1/1Çovdurhan görecim, könül diregim, } \\
\text { 1/2Sen vapat bolup sen, zarlar içinde, }\end{array}$ & $\begin{array}{l}\text { Çowdur Han, görecim, göwün diregim, } \\
\text { Sen wepat bolup sen, zarlar içinde, }\end{array}$ \\
\hline $\begin{array}{l}\text { 3/3Gara daglar dözmey, başın galdırdı, } \\
\text { 3/4Çeşmin (gözim) yaşı, duman garlar içinde. }\end{array}$ & $\begin{array}{l}\text { Pelek seniñ gül ömrüñi soldurdı, } \\
\text { Hazan degdi, now gunçañ yoldurdı }\end{array}$ \\
\hline
\end{tabular}

\section{Soňudagı}

\begin{tabular}{|l|l|}
\hline Stavropol & Türkmenistan \\
\hline 1/3Duşman görse, dövdüleşdi, & Duşman görse,dövüşerler, \\
\hline 3/4Bek yagşıdır yoluñ seniñ. & Naybadaydır yoluñ seniñ. \\
\hline 4/3Tövreginde harman gursak, & Töreyitde harman gursak, \\
4/4Aş dökmek hıyalıñ seniñ. & Nan dökmek hıyalıñ seniñ. \\
\hline 5/4Neçik geçdi halıñ seniñ. & Niçik geçdi halıñ seniñ. \\
\hline
\end{tabular}

\section{Otur-Turuş1ñ Görüñ (2014:329)(2. dörtlük eksik)}

\begin{tabular}{|c|c|}
\hline Stavropol & Türkmenistan \\
\hline $\begin{array}{l}\text { 2/1Bir pul düşse bir uflasın (çomart) çoluna } \\
\text { 2/2Gövsün açıp, gezer g1şın eline, } \\
\text { 2/3Hacatlı bolsañız giza, keline, } \\
\text { 2/4Edebin, erkanın, oturşın görüñ! }\end{array}$ & $\begin{array}{l}\text { Bir pul düşse bir üflasın goluna } \\
\text { Gövsün açıp, gezer gışın yeline, } \\
\text { Hırıdar bolsañız gıza, geline, } \\
\text { Edebin, erkamın, oturşın görüñ! }\end{array}$ \\
\hline $\begin{array}{l}\text { 3/1Tañrı bizar, biliñ, zekatsız baydan, } \\
\text { 3/3Merde bir iş düşse, görer hudaydan, } \\
\text { 3/4Namardın kişiden (yoldaşından) (hemradan) } \\
\text { görüşin görüñn! }\end{array}$ & $\begin{array}{l}\text { Tañrı bizar erer zekatsız baydan, } \\
\text { Merde her iş düşse, görer hudaydan, } \\
\text { Namardıñ hemradan görüşin görüñn! }\end{array}$ \\
\hline 4/2Köñli g1ş bolmaz, herne yaz bolar, & Köñli g1ş bolmayın, dayım yaz bolar, \\
\hline 5/1Goç yigidiñ at-yarıgı şay bolsa, & Goç yigidiñ at-yaragı şay bolsa, \\
\hline $\begin{array}{l}\text { 6/2Gadırsız yat bilen garındaş bolup, } \\
\text { 6/4Hocanıñ, seyidiñ yirüşin görüñ̃! }\end{array}$ & $\begin{array}{l}\text { Gadırsız yat bile garındaş bolup, } \\
\text { Hocanıñ, seyidiñ yörüşin görüñ̃! }\end{array}$ \\
\hline
\end{tabular}

29. Malına Degmez(2014:339) (2.3. dörtlükler eksik)

\begin{tabular}{|l|l}
\hline Stavropol & Türkmenistan
\end{tabular}




\begin{tabular}{|l|l|}
\hline $\begin{array}{l}\text { 3/1Dövletli er gerek, söveşde serhoş, (parahat) } \\
\text { 3/2Yat bilen barışsañ, bolar sengardaş, } \\
\text { 3/3Yagşı ogul, yagşı hatın, hem gız gardaş, }\end{array}$ & $\begin{array}{l}\text { Bedew gerek-äre söveşde serhoş, } \\
\text { Yat bilen barışsañ, bolar garındaş, } \\
\text { Yagşı ogul, yagşı ayal, gız gardaş, }\end{array}$ \\
\hline $\begin{array}{l}\text { Söz bilmeseñ bileniñi aytmasañ, } \\
\text { Söz sözledip, söz aslına etmeseñ, } \\
\text { Yay çekende dogrı garap atmasan, } \\
\text { Ol okuñ nışanıñ yanına degmez. }\end{array}$ & Türkmenistan nüshasında yok. \\
\hline $\begin{array}{l}\text { 5/2İymek, içmek, minmek, guçmak, söhbet } \\
\text { 5/3Bir niceler, mıdam gılar tagatı, } \\
\text { 5/4Niçeleriñ,secdä başı değmez. }\end{array}$ & $\begin{array}{l}\text { İymek, içmek, münmek, guçmak, söhbeti } \\
\text { Bir niçeler, midam gılar tagatı, } \\
\text { Niçäniñ, secdä cay alına degmez. }\end{array}$ \\
\hline
\end{tabular}

30. Dövleti-Malı Bolmasa

\begin{tabular}{|l|l|}
\hline Stavropol & Türkmenistan \\
\hline 1/3亡́şleyuben iş bitirmez, & Goç yigidiñ adı çıkmaz, \\
\hline 4/3Duzı şor, düşmanı güyçli, & Duzı zor, düşmanı güyçli, \\
\hline
\end{tabular}

31. Yat Bolar (2014:382) (3. dörtlük eksik)

\begin{tabular}{|l|l|}
\hline Stavropol & Türkmenistan \\
\hline 1/3Gaçar agañ, iniñ, bomaz hatırıñ, & Gaçar agañ, iniñ, bomaz hatırañ, \\
\hline 2/1Garıp ayak yalañgaç, kendir guşakdır, & Garıp ayak yalañ, kendir guşakdır, \\
2/3Garıplar at minsede eşekdir, & Garılar at münüp, depse-eşekdir, \\
2/4Dövletliler eşek minse- at bolar. & Dövletliler eşek münse- at bolar. \\
\hline 3/1Bir dilek dileseñ, mähümiñ bitmez, & Bir dileg dileseñ, möhümiñ bitmez, \\
3/2Dostuñ ıllas bilen merhamet etmez, & Dostuñ ihlas bilen mürevvet etmez, \\
3/3Märekede aydan sözüñ tutılmaz, & Märekede aydan sözüñ jay tutmaz, \\
3/4Dinlemezler, aydan sözüñ “yel” bolar. & Diňlemezler, aydan sözün “bat” bolar. \\
& \\
\hline 4/1Göreş bir abray, uruş bir destdir, & Göreş bir abraydır, uruş bir destdir, \\
4/2Kişini kem sanan- özi näkesdir, & Kişini kemsiden-özi näkesdir, \\
4/3Akıllılara gibat etmek hebesdir, & Bir mömine gibat etmek hebesdir, \\
4/4Gıbatkeşiñ baran yeri ot bolar. & Gibatkeşiñ gazananı ot bolar. \\
\hline 5/1Magtımgulı, şükür et sen, hudaga, & Magtımgulı, şükür eylegil, hudaga, \\
\hline
\end{tabular}

\section{Garıplık (3.4. dörtlükler eksik)}

Türkmenler bu şiiri 18. yüzyıl şairi Talıbı'nın şiiri olarak göstermektedir. Kafkas Türkmenleri son dörtlükte Mahtumkulu'nun mahlasını kullanmışlar.

\begin{tabular}{|l|l|}
\hline Stavropol & Türkmenistan \\
\hline 1/2Gün-günden süyrenip geldi garıplık, & Gün-günden sürünüp geldi garıplık, \\
1/4Anim alıp, bagrım dildi garılık. & Igtıyarım goldan aldı garıplı. \\
\hline 2/1Baylık bir el kiri, yuvulsa gider, & Baylık bir el kiridir, yuvulsa gider, \\
2/2Garıp üçin açlı ölümden beter, & Garıba açlıkdır zäherden beter, \\
Barlı gol uzatsa, heryana yeter, & Baylıel uzatsa uzatsa, heryana yeter, \\
2/4Hasretiñ cepasın çekdi garıplık. & Golum baglap, bagrım dildi garıplık. \\
\hline
\end{tabular}




\begin{tabular}{|c|c|}
\hline $\begin{array}{l}\text { 3/1Deñ-duşı görende gayra bakar sen, } \\
\text { 3/2Yoksuzlııı yatlap, iza basar sen, } \\
\text { 3/3Sözüñ ile sıgmaz, özüñ yeser yesir sen, } \\
\text { 3/4Hatarda gurı sal gıldı garıplı. }\end{array}$ & $\begin{array}{l}\text { Deñ-duşı görende gayra teser sen, } \\
\text { Yoksullık yat edip, için gısar sen, } \\
\text { Sözüñ ile sıgmaz, özüñ öser yesir sen, } \\
\text { Hemme dertden yaman boldı garıplık. }\end{array}$ \\
\hline $\begin{array}{l}\text { Baylarıñ gapısı bekdir, çaglıdır, } \\
\text { "Aç" desen açılmaz, bentdir, bağlıdır, } \\
\text { Diliñ gıskadır, yürek daglıdır, } \\
\text { Uyadı, hayanı aldı garıplık. }\end{array}$ & Türkmenistan nüshasında yok. \\
\hline $\begin{array}{l}\text { 5/1 Magtımgulı, köñli gamlı bolmagıl, } \\
\text { 5/2Zınhar, alla adın dilden almagıl, } \\
\text { 5/3Berimsiz-bahıl baylardan tema kılmagıl, } \\
\text { 5/4İle gelen mähnet, boldı garılık. }\end{array}$ & $\begin{array}{l}\text { Talıbı,diyrköñlüm gamlı bolmagıl, } \\
\text { Zınhar, Alla adın dilden salmagıl, } \\
\text { Görümsiz baylardan umıt kılmagil, } \\
\text { Bir zaman eglenmez, geçer garıplık. }\end{array}$ \\
\hline
\end{tabular}

\section{Barı Bolmasa (1959:46) (3.4.6. dörtlükler eksik)}

\begin{tabular}{|l|l|}
\hline Stavropol & Türkmenistan \\
\hline 1/3Yüz tümenlik sözün zata saymazlar, & Yüz tümenlik sözün şaya almazlar, \\
\hline 2/3Otlı, suvlı tamer andan yagşıdır, & Otlı, suvlı, tamug andan yagşıdır, \\
\hline 3/3Yaman gılık dostı duşman gıladır, & Yaman gıllk dostı duşman kıladır, \\
\hline 4/2Her namarda sargaydırma yüzüñni, & Her namarda sarartmagıl yüzüñni, \\
\hline
\end{tabular}

\section{Kaýsı Bilinmez}

\begin{tabular}{|c|c|}
\hline Stavropol & Türkmenistan \\
\hline 1/1Derdim bardır diyarımdan, dövrümden, & Derdim köpdir diyarımdan dövrümden, \\
\hline 3/3Hatınlarda uyat, gızda şerim yok, & Hatınlarda haya, gızda şerim yok, \\
\hline $\begin{array}{l}\text { 4/1Kişiniñ malına gözün atarlar, } \\
\text { 4/2Tagsip edip, köñlde kine doldırarlar, } \\
\text { 4/3Bir-birini nähak yerden öldirerler, }\end{array}$ & $\begin{array}{l}\text { Kişiniñ malına gözün aldırlar, } \\
\text { Täsip edip, köñlde kine doldırlar, } \\
\text { Bir-birini nähak yere öldirler, }\end{array}$ \\
\hline $\begin{array}{l}\text { 5/1Magtımguli, can mahmandır,gövde läş, } \\
\text { 5/3Bu eyamda baş-ayakdır, ayak-baş, }\end{array}$ & $\begin{array}{l}\text { Magtımgulı, can mıhmandır, gövre läş, } \\
\text { Bu eyyamda baş-ayakdur, ayak-baş, }\end{array}$ \\
\hline
\end{tabular}

\section{Ay-Günüñiz Batmaga (2014:286)(2.5.dörtlükler eksik)}

\begin{tabular}{|c|c|}
\hline Stavropol & Türkmenistan \\
\hline $\begin{array}{l}\text { 1/1 Altmış yaşan, yetmiş yılkı sopular! } \\
\text { 1/3Çöl yerlerde tazı görmän tilkiler, } \\
\text { 1/4Hıyal eder yatan şiri basmaga. }\end{array}$ & $\begin{array}{l}\text { Altmış yaşlı, yetmiş yılkı sopular! } \\
\text { Çöl-derede tazı görmän tilkiler, } \\
\text { Hıyal eder yatan şiri atmaga. }\end{array}$ \\
\hline $\begin{array}{l}\text { 2/1Agsak keyik yüz torsuga tutdurmaz } \\
\text { 2/2Şir balası togsan tilkä tutdırmaz, } \\
\text { 2/3Öli yılan müñ kelpezä (suliçan) yutdurmaz } \\
\text { 2/4Akıl gerek bu işlere yertmege }\end{array}$ & $\begin{array}{l}\text { Agsak keyik yüz torsuga tutdırmaz } \\
\text { Şir beçesi togsan tilkä tutdırmaz, } \\
\text { Öli yılan müñ kelpezä yuvtdurmaz } \\
\text { Hanı aklın bu işlere yertmege }\end{array}$ \\
\hline
\end{tabular}




\begin{tabular}{|c|c|}
\hline $\begin{array}{l}\text { 3/3Müñüürlercem bolup, yıkdı Käbäni, } \\
\text { 3/4Yezit (Arabistan'da Ala garşı adam) gitdi } \\
\text { agaçların satmaga. }\end{array}$ & $\begin{array}{l}\text { Kapırlar kast edip, yıksa Käbäni, } \\
\text { Müňkür barar agacını satmaga. }\end{array}$ \\
\hline $\begin{array}{l}\text { 4/1Yüregim sabırdan, gitdi kakarım, } \\
\text { 4/2Yaman işdir, yaman söz är-ärden! } \\
\text { 4/3Pikar gelip men, beyle diyardan (ülkeden, } \\
\text { yuvurtdan). } \\
\text { 4/4Rıza bolup men, başım alıp gitmege. }\end{array}$ & $\begin{array}{l}\text { Yüregim sabırdan, gider karardan, } \\
\text { Yaman işdir, buguz bolmak är-ärden! } \\
\text { Bizara gelip men, beyle diyardan, } \\
\text { Cür bolup men, başım alıp gitmäge. }\end{array}$ \\
\hline $\begin{array}{l}\text { 5/1Magtımgulı, bildim: bagtım garadır, } \\
\text { 5/2 Ganımım güyçlüdir, ıkbalım keçdir, } \\
\text { 5/3(bagtım kemdir) } \\
\text { 5/4 Niyetim Käbedir, hıyalım Hacdır, } \\
\text { Ikrarım bar, haç tovabın etmege. }\end{array}$ & $\begin{array}{l}\text { Magtımgulı, bildim, bagtım biweçdir, } \\
\text { Gıbatım güyçlüdir, ıkbalım keçdir, } \\
\text { Niyetim Käbedir, hıyalım Haçdır, } \\
\text { Ihlasım bar, haç togabın etmäge. }\end{array}$ \\
\hline
\end{tabular}

36.Döke Başladı (2014:326) (3.4. dörtlükler eksik)

\begin{tabular}{|c|c|}
\hline Stavropol & Türkmenistan \\
\hline $\begin{array}{l}\text { Gömüldi deryalar, yıkıldı daglar, } \\
\text { 1/2 Yetimler gözyaşın töke başladı, } \\
\text { 1/3Orrapsıdan bolan, haramhoz begler, } \\
\text { Her dagbir yanından yıka başladı. }\end{array}$ & $\begin{array}{l}\text { Gömüldi deryalar, yıkıldı daglar, } \\
\text { Yetimler gözyaşın döke başladı, } \\
\text { Orrapsıdan bolan, haramhor begler, } \\
\text { Yurdı bir yanından yıka başladı. }\end{array}$ \\
\hline $\begin{array}{l}\text { 2/3Kazılarıñ käri, temäkidir, nasdır } \\
\text { 2/4Akça görse gıza çöke başladı. }\end{array}$ & $\begin{array}{l}\text { Kazılarıñ käri, çay, nasdır, } \\
\text { Bir bozuk nışana tuta başladı. }\end{array}$ \\
\hline $\begin{array}{l}\text { 3/1Dünyäde süythorıñ pul yıkmagakasdı, } \\
\text { 3/2Baylarıñ malları zekatsız ösdi, } \\
\text { 3/3Taba ediñ, gözüm bir yamanlık ärdi, } \\
\text { 3/4Dost dostuñ öyüni yıka başladı. }\end{array}$ & $\begin{array}{l}\text { Dünyäde süythorıñ pul yıgmaga derdi, } \\
\text { Baylarıñ malları bizekat erdi, } \\
\text { Toba ediñ, gözüm bir yaman gördi } \\
\text { Bi-günä, bir-birin yaka başladı. }\end{array}$ \\
\hline 4/4Herne tapsa, dınmay yıga başladı. & Herne tapsa, dınmay dıka başladı. \\
\hline
\end{tabular}

\section{Gaça Başladı (2014:319) (5.6.7. 9. dörtlükler eksik)}

\begin{tabular}{|l|l|}
\hline Stavropol & Türkmenistan \\
\hline 1/1 İmdi bildim zamananı̃̃ azgııın, & İndi bildim zamananıñ azanın, \\
1/3Gayta asılsızlar asılzadalardan, & Gayta bedasıllar asılzadadan, \\
1/4Edep saklaman, töre çıka başladı. & Pisint etmey, töre geçe başladı. \\
\hline 2/1Rıya boldı köpün okan namazı, & Irya boldı köpüň okan namazı \\
2/2Tanrı hiç birinden bolmadı razı. & Taňrı hiçbirinden bolmadı razı \\
2/3Pıgamber ornında otıran kazı, & Pıgamber ornunda oturan kazı \\
2/4Akça üçin elin aça başladı. & Para üçin elin aça başladı. \\
\hline 3/2Bir pıl üçin, müfti berer rovayat, & Bir pul üçin, müfti berer rovayat, \\
3/3Bil: bu işler- nışanası kıyamat, & Bil: bu işler- nışanayı kıyamat, \\
3/4Zalımlar tobasız öte başladı. & Zalımlar bitoba öte başladı. \\
\hline 4/1Pakırlar horlanıp, yüzün sarfaydıp, & Dadhahlar turuban, yüzün sarardıp \\
4/2Kazı töresin tapıp, reñgin gızardıp, & Kim töresin tapıp, reňňin gizardıp, \\
4/3Zalımlar mazlumıñarkasın gabardıp & Zalımlar mazluma sırtın gabardıp, \\
\hline
\end{tabular}




\begin{tabular}{|l|l|}
\hline 5/4Panıdan bakıya geçe başladı. & Panıdan bakıya göçe başladı. \\
\hline 6/1Kazı bolan bir cavapda durmadı, & Kazı bolan bir cogapda durmadı, \\
6/2Gice mähnet çekip, kitap görmedi, & Gice mihnet tartıp, kitap görmedi, \\
6/3Şerigat ugrunda dogrı yörmedi, & Şerigat sözünde dogrı yörmedi, \\
6/4Nebe üçin imansız öte başladı. & Nebs üçin imansız öte başladı. \\
\hline 7/2“Bäş gün” sınamaga yiberdi seni, & "Bäş gün” sınamaga iberdi seni, \\
7/3Sende ozal öten cannar ganı, & Senden burun öten cananlar hanı? \\
7/4Her kim navbatında öte başladı. & Her kim nobatında öte başladı. \\
\hline
\end{tabular}

38. Daman Galmadı (1959:118-120) (3.5.6. dörtlükler eksik)

\begin{tabular}{|l|l|}
\hline Stavropol & Türkmenistan \\
\hline 1/3Dövletli baylarınduz-tahamında & Dövletli baylarıň duz-hareminde \\
\hline 2/3Tanrıdan bihabar goşun uzatdı, \\
2/4Tanrını bir bilen merdan galmadı. & $\begin{array}{l}\text { Taňrıdan bihabar goşun uzatdı, } \\
\text { Taňrını bir bilen merdan galmadı. }\end{array}$ \\
\hline 3/3Öhli -dil dünyäden özün gutardı, & Ähli -dil dünyäden özün gutardı, \\
\hline $\begin{array}{l}\text { 4/2Yerden göterildi bereket-giya (peyda), } \\
\text { 4/3Dervuşlar tagatın eyledi rıya, }\end{array}$ & $\begin{array}{l}\text { Yerden götermedi bereket-giya, } \\
\text { Dervüşler tagatın eyledi rıya, }\end{array}$ \\
\hline $\begin{array}{l}\text { 5/2Burunkı yörüşen dostlarıñ ganı? } \\
\text { 5/3Abray bile tabşıragor bu canı }\end{array}$ & $\begin{array}{l}\text { Burunkı hemneşin dostlarıñ kanı? } \\
\text { Abray bile tabşıraver bu canı }\end{array}$ \\
\hline
\end{tabular}

39. Kul u Kal Bolar (3. dörtlük eksik)

\begin{tabular}{|l|l|}
\hline Stavropol & Türkmenistan \\
\hline 1/1Her kişiniñ iki bolsa hatını, & Her kişiniñ iki bolsa ayalı, \\
1/3Şatlık sürüp görecegi hal bolar. & Ovkat sürüp gördücegi hal bolar. \\
\hline 2/1Birin söyüp, birin eylese hor, & Birin söyüp, birin eylese naçar, \\
\hline 3/1Gahar eyläp, gelmez bolsa yanına, & Gahr eyläyip, gelmez bolsa yanına, \\
\hline 4/3Alla görkezmesin yaman hatını, & Eýäm görkezmesin yaman hatını, \\
\hline
\end{tabular}

\section{0. Çatıp Bolmayır (1959:95)(3. dörtlük eksik)}

\begin{tabular}{|c|c|}
\hline Stavropol & Türkmenistan \\
\hline 1/2Düybi bır bolmasa, çatıp bolmayır, & Düybi bir bolmasa, çatıp bolmayır, \\
\hline $\begin{array}{l}\text { 2/1Kiçkey zattan bolmaz beyik minara, } \\
\text { 2/2Yaman hatın duşsa bir yagşı ere, } \\
\text { 2/3Başın kesip, ganın töküp kenara, }\end{array}$ & $\begin{array}{l}\text { Kelte diňden bolmaz beyik minara, } \\
\text { Yaman heley duşsa bir yagşı äre, } \\
\text { Başın kesip, ganın döküp kenara, }\end{array}$ \\
\hline 3/1Pakırlar mal ister, baylar zer diyer, & Pakırlar mal istär, baylar zer diyer, \\
\hline $\begin{array}{l}\text { 4.Hatınıñ yamanı sırını gizlär, } \\
\text { Dogrını yaşrıp, yalanın sözlär, } \\
\text { Ol, şeytan azdırsa, başganı gözlär, } \\
\text { Asılha, pikrine yetip bolmayır. }\end{array}$ & Türkmenistan Nüshasında Yok. \\
\hline
\end{tabular}

\section{Mal Yagşı (2014:378)(4.5 dörtlükler eksik)}




\begin{tabular}{|l|l|}
\hline Stavropol & Türkmenistan \\
\hline 1/1Adam bolup adam gadrın bilmeyen, & Adam gadırın bilmän yören adamdan, \\
1/2Andan yene otlap yören mal yagşı, & Ondan ýene otlap yören mal yagşı \\
1/3Sözlegende söz magnasın bilmeyen, & Söz manısın bilmän sözlän adamdan, \\
1/4Ondan yene sözläp bilmez lal yagşı. & Ondan yene sözlemeyen lal yagşı. \\
\hline $\begin{array}{l}\text { 2/3Her bir yerde bir bazarsız şäherden, } \\
\text { 2/4Ondan yene bir gulap yatan çöl yagşı. }\end{array}$ & $\begin{array}{l}\text { Ey yaranlar, bir bazarsız şäherden, } \\
\text { Ondan ki bir güwläp yatan çöl yagşı. }\end{array}$ \\
\hline 3/2Yadından çıkarmaz bayramı-toyı, & Yadından çımayır bayramı-toyı, \\
\hline 4/3Yat illerde ayraçılık çekenden, & Yat illerde mısapırlık çekenden, \\
\hline $\begin{array}{l}\text { 5/2Bu dünyä tutdırmaz, düşmandır düypden, } \\
\text { 5/3Märekede peyda soñı gelmez, yaman sözden, } \\
\text { 5/4Andan yene bir şovlap osen yel yagş1. }\end{array}$ & $\begin{array}{l}\text { Bu dünyä tutdurmaz, çüýrükdir düypden, } \\
\text { An̆ırsı gelmeyen gurı, bat gepden, }\end{array}$ \\
& Andan yene bir şuwlap öten yelyagşı. \\
\end{tabular}

\section{Aňlamaz (1959:20-21) (2. dörtlük eksik)}

\begin{tabular}{|c|c|}
\hline Stavropol & Türkmenistan \\
\hline $\begin{array}{l}\text { 1/1 Asılsıza beglik yetse bir günde, } \\
\text { 1/2Alar avın, salar guşun aňlamaz } \\
\text { 1/3Yarlılıgı görmeyen uyatsız begler, } \\
\text { 1/4Pakırlarıñ gözde yaşın añlamaz. }\end{array}$ & $\begin{array}{l}\text { Bedasıza beglik yetse bir günde, } \\
\text { Alar avun, salar guşun aňlamaz } \\
\text { Yarlılıgı yörigen nurbatsız begler, } \\
\text { Pukaranın gözde yaşın añlamaz. }\end{array}$ \\
\hline 2/1Mertden dilek etseñ aydar: "yagşı bolar!" & Mertden dileg etseñ aydar:"hup bolar!" \\
\hline $\begin{array}{l}\text { 3/1Hak yoluna her kim hayır-1hsan kılsalar, } \\
\text { 3/3Namart duşman görse, gaygıdan öler, } \\
\text { 3/4Goç yiyitler dördin bäşin añlamaz. }\end{array}$ & $\begin{array}{l}\text { Hak yoluna her kim hayır-ıhsan kılar, } \\
\text { Namart duşman görse, gussadan öler, } \\
\text { Goç yiyitler tördün bäşin añlamaz. }\end{array}$ \\
\hline 4/1Magtımgulı, beg yanında söz başlar, & Magtımgulı, beg yanında til başlar, \\
\hline
\end{tabular}

\section{Gıbatkeş (1959:131-132)(3. dötlük eksik)}

\begin{tabular}{|l|l|}
\hline Stavropol & Türkmenistan \\
\hline $\begin{array}{l}\text { 1. Dörtlük } \\
\begin{array}{l}\text { Ömürün yele yiberme, azma yoluñdan, } \\
\text { (päliñden) }\end{array}\end{array}$ & Ömürüñ yele berme, azma yoluñdan, \\
\hline $\begin{array}{l}\text { 2. Dörtlük } \\
\text { Gähi buzdan tagtlar, otdan öyler, } \\
\text { Gatır dek çlyanlar, bugrı dek möler, }\end{array}$ & $\begin{array}{l}\text { Gähi buzdan tagtlar, ataşdan öyler, } \\
\text { Gatır dek çlyanlar, bugra dek möyler, }\end{array}$ \\
\hline $\begin{array}{l}\text { 3. Dörtlük } \\
\text { Gunahın agramı basar üstüñden, }\end{array}$ & Gunähıñ agramı basar üstüñnden, \\
\hline $\begin{array}{l}\text { 4.Dörtlük } \\
\text { Düşüben, hor bolsañ, görgül özünden, } \\
\text { Tiliñi tartmasaň haram sözüñnden, }\end{array}$ & $\begin{array}{l}\text { Düşüban, hor bolsañ, görgül özüñden, } \\
\text { Tiliñi çekmeseñ haram sözüñden, }\end{array}$ \\
\hline
\end{tabular}

\section{Nas Atan (4. dörtlük eksik)}

\begin{tabular}{|l|l|}
\hline Stavropol & Türkmenistan \\
\hline 1/2Köp yıgar sen, mıdam işiñ nas atan, & Köp aglar sen, mıdam işiñ nas atan, \\
1/4Galar dovzah içre, teniñ, nas atan, & Galar dovzah içre, läşiñ, nas atan, \\
\hline
\end{tabular}




\begin{tabular}{|c|c|}
\hline 2/2Aya hakıp, üç mısgalınatar sen, & Çala owup, üç misgaldan tartar sen, \\
\hline $\begin{array}{l}\text { 3/1Namaza duranda, üstüne akar, } \\
\text { 3/3“"Veyil” yılgasında (cayda) tütüniñ çıkar, }\end{array}$ & $\begin{array}{l}\text { Namaza duranda, üstüňe akar, } \\
\text { "Veyil" diygen cayda tütüniñ çıkar, }\end{array}$ \\
\hline $\begin{array}{l}\text { 4/2Gelse humar, imanını yandırar, } \\
\text { 4/4Zehir bolar içen aşıñ, nas atan! }\end{array}$ & $\begin{array}{l}\text { Gelse humar, imanıňı yandırar, } \\
\text { Murdar bolar içen aşıñ, nas atan! }\end{array}$ \\
\hline 5/1Her adamı görseñ, gizläp gaçar sen, & Bir adamı görseñ, gizläp gaçar sen, \\
\hline $\begin{array}{l}\text { 6/2Cınaza okamay, burnuñ dilerler, } \\
\text { 6/3Sakar (ziyaratdan dişda) diyen caya seni } \\
\text { soraralar } \\
\text { 6/4Niçik bolar, anda başıñ, nas atan. }\end{array}$ & $\begin{array}{l}\text { Cinaza okaman, burnuñ dilerler, } \\
\text { Sakar diygen caya seni salarlar, } \\
\text { Nara döner, içiň-daşıñ, nas atan. }\end{array}$ \\
\hline
\end{tabular}

\section{Armanım Galdı (2014:140)(2. dörtlük eksik)}

\begin{tabular}{|l|l|}
\hline Stavropol & Türkmenistan \\
\hline 3/2Gezdim ilimden daş bolup, & Gezdim ilimden uyalıp, \\
\hline 4/2Yörmedim cahanı yortup, & Yörmedim cahanı gezip, \\
4/3Zahmet çekip, azap görüp & Zahmet çekip, azar tartıp, \\
\hline
\end{tabular}

\section{Divanlarda Tespit Edilemeyen Şiirler}

\subsection{Panı Cahana}

Kimse bazar tutup, girdi dukana,

Kimsäni getirmez panı cahana,

Bag içinde kimi göyduñ erkana?

Dag içinde men misgine yurt kıldıñ.

Kim namaz okımaz, kim roza tutmaz,,

Kimse pälin açtar, gicesi yatmaz,

Kimse sözi adam canına yokmaz,

Kimseleriñ sözün kesapat kıldıñ.

Adam oglı ıglar, yürekde ahı, Diñlemez gardaşı, kadır hudahı, Kimselere vatan kıldıñ dovzahı, Kimselere behit mürevvet kıldıñ.

Mahtımgulı diýer, derdi halını, Soran bolmaz meniñ bu ahvalımı, Kimseleriñ toprak kılıp malını, Kimseler topragın zebertet kıldıñ.

\subsection{Sipatından Bellidir}

Her başı saçlını hatın dimäñiz, Hatın oldur, sıpatından bellidir, Kir saklamaz oğlanını, özüni, Gaşı, gözi, gabagından bellidir. 
Bir niçe hatınlar akılsız-akmak,

Her sözi eriniñ canını yakmak,

Ne hacatdır eriñ yüzüne bakmak,

Hayvan erur (hayvandır ol) gilıgından bellidir.

Yaman hatın manlay saçı top bolar,

Sözlände yaman sözi köp bolar,

İşiginiñ aldında çöp-çör köp bolar,

Çıkarmaz külüni, ocağından bellidir.

Tagrıpın aydalı yagşı hatınıñ,

Yagşınıñ kadrın bilgil çın anıñ,

Hazırdır gelene aş bilen nanıñ,

Çın keyvanı (saturn) saçağından (destarhanından) (destemal) bellidir.

Yagşı hatın güler eriniñ yüzüne,

Müñ can gurban aniñ her bir sözüne,

Cennet bolar dergayına-özüne,

Gazanından, tabagından bellidir.

Magtımgulı, goluñ tartgil haramdan,

İmanıña kemçilik eter zıyandan,

Yagşıllıg1 umut etli yamandan,

Bolcak oglan yaşlıgından bellidir.

\subsection{Yarım Görünmez}

Turgul, Cebrayıldan habar sörayın

Ne sebäpdir gözel yarım görünmez?

Telmerit gapıña günde barayın,

Ähdi-peyman, ol ıkrarım görünmez.

Pelek asıyasın (rahatın) bikarar kılmış

Namısdan daş düşüp, hakdan uyalmamış,

Yiğitler gajayıp, goca (lan) yigidemiş,

Çıragım öçüpdir, narım görünmez.

Bahıllar mert bolıp, geda şa bolup,

Mertler namart bolup, pir dinden galıp,

Azanlar kesilip, mescit yapılıp,

Hakdan özge bir azarım görünmez.

Mahtımgulı aydar, bu ne hekayat,

İl barı alımdır, tutmaz nesihat,

Asmandan inıpdır zemine apat (kelamat)

İsa, Mäti, Malik ajdar görünmez. 


\section{Nazar Bahşının Defterindeki Mahtumkulu Destanının Sonunda Yer Alan Leyli Mecnun Gazeli \\ Leyli Mecnun Gazeli}

Kadır Alla! Müñ bir adıñ hakından,

Cefası köp bu dünyäden al meni,

On sipagiñ, yeke zatıñ hakından,

Cefası köp bu dünyäden al meni

Kimse gelip munda yetdi murada,

Maksat yolin tapman kaldı arada,

Mundan artık men galmayın izaga,

Cefası köp bu dünyaäden al meni

Megder bu dönyanıñ kemsigi biter,

Öz lutgıña alıp, gövnimi köter,

almasañ, günden-gün bänetim artar,

Cefası köp bu dünyaäden al meni.

Miskin başım köp cefaga batırdı,

Bıçagını istıhana yetirdi,

Bir şat edip, müñ igladıp getirdi,

Cefası köp bu dünyaäden al meni.

Haşık bolan, ışık odına dalaşar,

Canın berip, cenanına ulaşar,

Leyliden galmanı, ölsem yaraşar,

Cefası köp bu dünyaäden al meni.

Ruhsat bergil, can koşılsın canına,

Vasil bolsın, ol gövheriñ kanina,

Gövün kaşı pervaz eder yanına

Cefası köp bu dünyaäden al meni.

Mecnun aydar: hak yetişsin hallara,

Aklım hayran, gözüm geryan yollara,

İndi bakman, sagim bile sollara,

Cefası köp bu dünyäden al meni

\section{SONUÇ}

Mahtumkulu elyazmalarının çoğunluğu, Türkmenistan'da Türkmenbaşı Milli El Yazmaları Enstitüsün'de bulunmaktadır. Üç yüze yakın el yazmasında bulunan şiirler, halkın alayabileceği bir dille yazıldığı için bu şiirler kolayca ezberlenmiş ve nesiller arasında aktarılabilmiştir. Mahtumkulu'nun şiirleri, bahşılar tarafından toylarda, meclislerde ezgili bir şekilde söylenmiştir. Kuzey Kafkasya Türkmenleri arasında da meşhur olan Mahtumkulu şiirleri genel olarak Türkmenistandaki nüshalara benzemekle birlikte, aralarında bazı ses, şekil ve kelime farklılıkları vardır. Kuzey Kafkasya nüshasındaki şiirlerinin bazı beyitlerinin eksik, bazı beyitlerin fazla, bazı beyitlerin ise ses ve şekil olarak Türkmenistan'da yayınlanmış olanlardan farklı olduğu görülmüştür: “Köp yıgar sen, mıdam işiñ nas atan-Köp aglar sen, mıdam işiñ nas atan"

"Galar dovzah içre, teniñ, nas atan- Galar dovzah içre, läşiñ, nas atan" vb.

Mahtumkulu'nun kendi el yazmalarının günümüze ulaşmaması onun eserlerinin ayrı ayrı 
yazıcılar tarafından kaleme alınması da sözcüklerin anlaşılmasını belli derecede zorlaştırmaktadır. Bu nüsha çözüme kavuşturulamayan, anlaşılmayan bazı beyitleri çözümlemede faydalı olacağı düşünülmektedir. Bu şiirler vasıtasıyla da Mahtumkulu'nun birbirinden çok uzak coğrafyalarda yaşayan Türkmenler arasında bir gönül köprüsü vazifesi görmüş olduğu görülmektedir.

\section{SUMMARY}

Mahtumkulu, recognized as the greatest poet of Turkmen literature. Mahtumkulu was a poet and social leader who was not indifferent to the social problems of his era and tried to lead and give hope to his society. The poems of Mahtumkulu cover all aspects of Turkmen way of life. Mahdumkulu has created from the Turkmen court of literature written in the comprehensive and written monuments by his poetry. Mahtumkulu is a spiritual healer of the human soul. Admonition and advice, expressed by the poet in his verces, serve as a healing balm fort he human spirit, as wings for the aspiring soul; as an engine for new achievments. It is for this reason that despite the passage of many epochs, and despite the transformations of life styles, the value of the poetry is not lost but rather becomes more and more significant.

In the eighteenth century there was a significant abstacle for realization of the fundemental social idea of Mahtumkulu to unite all Turkmen tribes. During that century there was a strong discord among many diffrent Turkmen tribes, and each tribe had to search for its own way of survival.

Stavropol Turkmens, who is called as Truhmen by Russian Turcologists, went out from Mangışlak and settled Caucasus then Stavropol and around. During Stavropol Turkmens, travelling to Caucasus and after settled Stavropol, have been in touch with Nogays, Kalmuks, Tatars, Kumuks, Kirghizs, Kazakh and made neigbourhood. Stavropol Turkmens are clans of Söyünacacı, İgdir and Çovdur. Turkmens, depending on Russian policies, in order to adapt quickly to Russian culture, are provided live with especially Russian, Tatar and Nogai. Russian, did not recognize Turkmen the right to education in their own language. As a result, Turkmen have started to lose their language. Tatar and Russian researchers called as Truhmens to Turkmens who lives Stavropol and around and called as Truhmenish to their language. Turkmens did not adopted this Truhmen name. Stavropol Turkmen Turkish, is one of Turkish dialect will be lost the near future. Stavropol Turkmen Turkish has a special place among Turkish languages in terms of has properties of both East and West Turkish. In language of Stavropol Turkmen, some forms are seen which come from Old and Middle Turkish have been saved in our day. It is possible to see Stavropol Turkmen Turkish, under the influence of Kipchak dialects, the effects of these dialects in some morphological constructions. In this paper, Stavropol Turkmen Turkish obvious morphological differences have been tried to reveal from Turkmenistan Turkish writing language.

As well as being loved by all the Turkmens who have been ruled, Stavropol is a well-known and wellliked poet. In this study, the copies of Mahtumkulu's poems known between Turkmenistan and Turkmen of the North Caucasus will be compared. In addition, Mahtumkulu poems that are not found in the Turkmenistan version will also take place. The Mahtumkulu poetry, which is also famous among the Turkmen of the North Caucasus, is generally similar to the manuscript in Turkmenistan, but there are some differences in sound, shape and vocabulary. Some of the couplets of the poems in the Northern Caucasus are missing, some couplets are different, some couplets are different in sound and form from those published in Turkmenistan. The fact that Mahtumkulu's own manuscripts do not arrive on a day-today basis and his works are taken separately by the writers makes it difficult to understand the words at once. 


\section{KAYNAKLAR}

AŞIROV, Annakurban (1984), Magtımgulının̆ Golyazmalarını̌ Tesviri, Ilım:Aşgabat.

AŞIROV, Annakurban (2012), Mahtumkulu Firaki: Türkmen Halkının Millî Gururu, Modern Türklük Araştırmaları Dergisi. Cilt 9 (4). Aralık. s. 7-22. Ankara.

AZMUN, Yusuf (2012). Türkmen Şair Magtımgulı ve Onun Eserleri Hakkında Bilinmesi Gereken Konular, Belleten, 2012(1), s.85-122.

BİRAY, Himmet (1992), Mahtumkulu Divanı, Ankara: Kültür Bakanlı̆̆g Yayınları.

CANKURT, Hasan (2013), Mahtumkulu Firâki'nin Şiirlerinde Muhteva,Turkish Studies, Vol. 8/9. s. 911-953.

ÇARIYEV, M. (1989), Magtımgulı ve Aydım Saz Sungatı, Magtımgulı-250,Şahır Hakında Ilmı Dokladlar, Makalalar ve Habarlar,s.276-284, Aşgabat:Ilım.

ÇETİN, Ayşe Y., Çetin İsmet (2015), Mahdumkulu Düşüncesinde Türklük,Uluslar arası Mahtumkulu Firaki Sempozyumu Bildiri Kitabl,s.82-88.

ERDEM, M. (2012), Mahtumkulu'nun Şiir Dünyasının Anlam Yönü,Modern Türklük Araştırmaları Dergisi, Cilt 9(4). s. 72-81.

GARRIYEV, Baymuhammet Atalıyeviç (1959), Magtımgull, Türkmen Döwletneşir: Aşgabat.

GARRIYEV, S. A. (1975), Türkmen Edebiyatını̃̃ Tarıhı- Tom II. Aşgabat: Ilım.

GULLA, Nazar (1998), Türkmenin Manevi Kalesi, Türk Lehçeleri ve Edebiyatları Dergisi, Sayı 18, Tömer Dil ve Öğretim Merkezi, Nisan 1998, Ankara: Cem Ofset.

KÖPRÜLÜ, Fuad (1976), Türk Edebiyatında İlk Mutasavvıflar, Ankara: Diyanet İşleri Başkanlığı Yayınları.

KÜRENOV, S. (1989), Magtımgulı Stavropol Türkmenleriniň Arasında, Magtımgulı-250, Şahır Hakında Ilmı Dokladlar, Makalalar ve Habarlar, S.72-83, Aşgabat:Ilım.

SARI, Berdi (2008), Mahtumkulu'nun Şiirsel Coğrafyası,Uluslararası Türk Dili Kurultayı Bildirileri, Cilt IV. S. 3809-3820, Ankara:TDK Yayınları.

TÜRKMEN, Fikret (2009), Türk Edebi Geleneğinde Yunus Emre, Karacaoğlan, Mahtumkulu Çizgisi,Milli Folklor, Sayı, 84. s. 18-22.

TEMIZKAN, Mehmet (2010), Onsekizinci Yüzyılın Şartları İçinde Mahtumkulu,Türk Dünyası Incelemeleri Degisi, Cilt 10 (1). s. 173-184.

YILMAZ, Hayati (2006), Mahdumkulı'nın Divanı'nın Nüshaları ve Türkmenbaşı Milli Elyazmaları Enstitüsü 400-E Numarada Kayıtlı A Nüshasında Bulunmayan Şiirleri, Modern Türklük Araştırmaları Dergisi, Cilt 3 (2), s. 86-156, Ankara. 